\title{
Sensitivity Approach for the Effective location of TCSC in a Deregulated Electricity Market
}

\author{
B.Likhitha ${ }^{1}$, J.Srinivasa Rao ${ }^{1}$, J.Amarnath ${ }^{2}$ \\ ${ }^{I}$ Department of Electrical and Electronics Engineering, QIS College of Engg \& Technology, Ongole. \\ ${ }^{2}$ Department of Electrical and Electronics Engineering, JNTUH College of Engg \& Technology, Hyd.
}

\begin{abstract}
In a deregulated electricity market it may always not be possible to dispatch all of the contracted power transactions due to congestion of transmission corridors. In a competitive electricity market, congestion occurs when transmission network is unable to accommodate all of the desired transactions due to the violation of system operating limits. Congestion relief can be handled using FACTS device such as TCSC, where transmission capability will be improved. Based on reduction of total system reactive power loss optimal location for the placement of these devices. Congestion management by Transmission Line Relief (TLR) sensitivity method was also examined for IEEE 9 bus system. The approach for this problem was carried out with the help of Power World Simulator software.
\end{abstract}

Keywords: Congestion, Deregulated power system, TCSC, Reduction of reactive power losses, Transmission Line Relief (TLR) sensitivity.

\section{INTRODUCTION}

Power industry is moving rapidly from regulated conventional setup to a deregulated environment. The main objective of the deregulation of power industry is to introduce competition among the power producers and prevent monopolies. Congestion is a consequence of network constraints characterizing a finite network capacity that precludes the simultaneous delivery of power from an associated set of power transactions [5]. When the producers and consumers of the electric energy desire to produce and consume in amounts that would cause the transmission system to operate at or beyond one or more transfer limit, the system is said to be congested.

Congestion is also defined as when the transmission network is unable to accommodate all of the desired transactions due to the violation of system operating limits. Line outages or higher load demands are the causes of congestion in the transmission network. Congestion occurs in both vertically bundled and unbundled systems but the management in the bundled system is relatively simple as generation, transmission and in some cases, distribution systems are managed by one utility. The management of congestion is somewhat more complex in competitive power markets and leads to several disputes.

Different techniques are used in many papers for solving the congestion problem. In [5] coordination between TCSC and SVC is investigated via Real Genetic Algorithm technique to increase the power transfer. In [6] Ashwini kumar proposed a Zonal based congestion management approach based on Real and Reactive power Rescheduling. In [11] an algorithm for congestion management based on optimal power flow framework and using TCSC has been proposed.

In [14] modelling of TCSC and a sensitivity based approach for optimal location of TCSC is proposed. In [15] two methods such as LMP difference method and congestion rent contribution methods are proposed for the

Placement of series FACTS devices like TCSC to reduce congestion.

FACTS devices are utilized as one of the method which can reduce the transmission congestion and leads to better using of existing grid infrastructure. FACTS devices, especially series FACTS devices like TCSC are considered one such technology which reduces transmission congestion.

Transmission Line Relief (TLR) sensitivities can also be used for the purpose of congestion alleviation by load curtailment.

In this paper a method for Congestion management have been suggested based on Load Curtailment using TLR sensitivity method and based on reduction of total system reactive power losses with the use of FACTS devices.

\subsection{Static modelling of TCSC}

\section{PROBLEM FORMULATION}

Thyristor controlled series compensators (TCSC) are connected in series with the lines. The effect of a TCSC on the network can be seen as a controllable reactance inserted in the related transmission line that 
Sensitivity Approach for the Effective location of TCSC in a Deregulated Electricity Market

compensates for the inductive reactance of the line. This reduces the transfer reactance between the buses to which the line is connected. This leads to an increase in the maximum power that can be transferred on that line in addition to a reduction in the effective reactive power losses. The series capacitors also contribute to an improvement in the voltage profiles.

Figure 1. Shows a model of a transmission line with a TCSC connected between buses $i$ and $j$. The transmission line is represented by its lumped $\pi$-equivalent parameters connected between the two buses. During the steady state, the TCSC can be considered as a static reactance $-j x c$. This controllable reactance, $x c$, is directly used as the control variable to be implemented in the power flow equation.

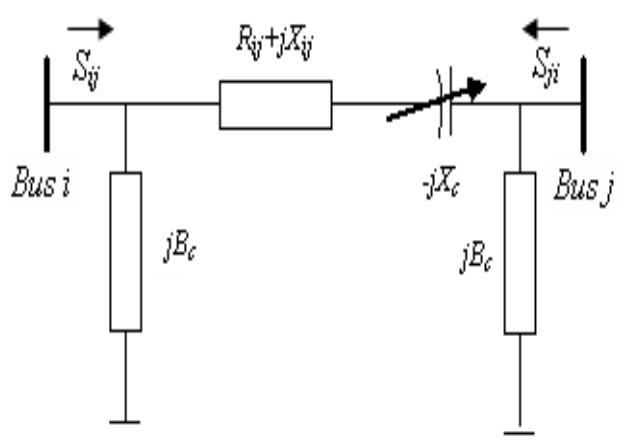

Fig2.1. Model of TCSC in a transmission line.

The following equations are used to model the TCSC.

Let the voltages at bus $i$ and bus $j$ are represented by $V_{i}\left\llcorner\delta_{i}\right.$ and $V_{j}\left\llcorner\delta_{j}\right.$ respectively. The complex power from bus $i$ to $j$ is

$\mathrm{P}_{\mathrm{ic}}=\mathrm{V}_{\mathrm{i}}^{2} \Delta \mathrm{G}_{\mathrm{ij}}-\mathrm{V}_{\mathrm{i}} \mathrm{V}_{\mathrm{j}}\left[\Delta \mathrm{G}_{\mathrm{ij}} \operatorname{Cos} \delta_{\mathrm{ij}}+\Delta \mathrm{B}_{\mathrm{ij}} \operatorname{Sin} \delta_{\mathrm{i}}\right]$

$\mathrm{P}_{\mathrm{jc}}=\mathrm{V}_{\mathrm{j}}^{2} \Delta \mathrm{G}_{\mathrm{ij}}-\mathrm{V}_{\mathrm{i}} \mathrm{V}_{\mathrm{j}}\left[\Delta \mathrm{G}_{\mathrm{ij}} \operatorname{Cos} \delta_{\mathrm{ij}}+\Delta \mathrm{B}_{\mathrm{ij}} \operatorname{Sin} \delta_{\mathrm{ij}}\right]$

$\Delta \mathrm{G}_{\mathrm{ij}}=\frac{x_{c} r_{i j}\left(x_{c}-2 x_{i j}\right)}{\left(r_{i j}^{2}+x_{i j}^{2}\right)\left[r_{i j}^{2}+\left(x_{i j}-x_{c}\right) 2\right]}$

$$
\Delta \mathrm{B}_{\mathrm{i}}=\frac{-x_{c}\left(r^{2}-x_{i j}^{2}+x_{c} x_{i j}\right)}{\left(r_{i j}^{2}+x_{i j}^{2}\right)\left[r_{i j}^{2}+\left(x_{i j}-x_{c}\right) 2\right]}
$$

\subsection{Reduction of total system VAR power loss}

Here it is looked at a method based on the sensitivity

of the total system reactive power loss $\left(\mathrm{Q}_{\mathrm{L}}\right)$ with respect to the control variables of the FACTS devices. For the device TCSC considered the following control parameter:

Net line series reactance $\left(X_{i j}\right)$ for a TCSC placed between buses $i$ and $j$, sensitivity factors with respect to the control variable may be given as follows:

Loss sensitivity with respect to control parameter $\mathrm{X}_{\mathrm{ij}}$ of TCSC placed between buses $\mathrm{i}$ and $\mathrm{j}$,

$$
a_{i j}=\frac{\partial Q_{L}}{\partial X_{i j}} .
$$

The loss sensitivities with respect to $X_{\mathrm{ij}}$ can be computed as:

$$
a_{i j}=\frac{\partial Q_{L}}{\partial X_{i j}}=\left[V^{2}{ }_{i}+V^{2}{ }_{j}-2 V_{i} V_{j} \cos \left(\delta_{i}-\delta_{j}\right)\right] \frac{R_{i j}^{2}-X^{2}}{\left(R_{i j}^{2}+X_{i j}^{2}\right)^{2}}
$$

\section{SELECTION OF OPTIMAL PLACEMENT OF FACTS DEVICES}

Using the loss sensitivities as computed in the previous section, the criteria for deciding device location might be stated as follows:

1. TCSC must be placed in the line having the most positive loss sensitivity index $a_{i j}$.

The procedure is shown in below flow chart fig 2.2 


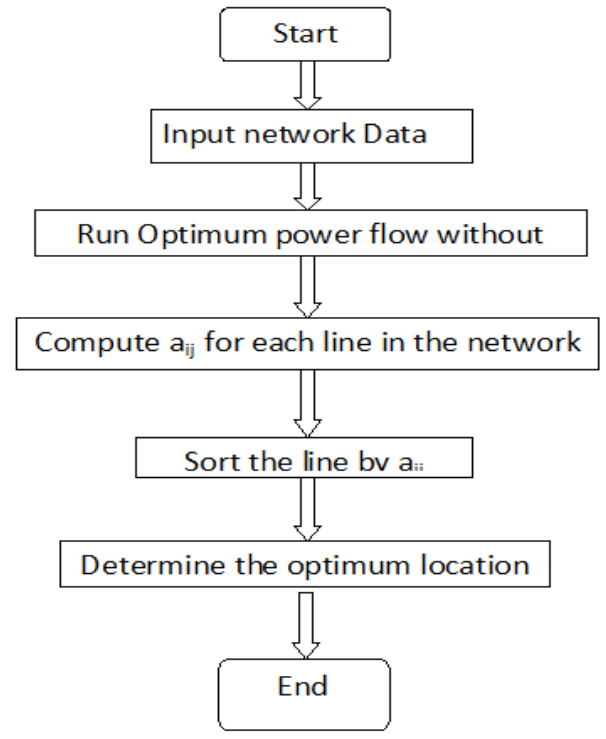

Fig:3.1 Flow chart for proposed method in effective location of TCSC

\section{LOAD CURTAILMENT BASED ON TLR SENSITIVITIES}

TLR sensitivities can be used for the purpose of congestion alleviation by load curtailment. TLR sensitivities are considered as inverse of power transfer distribution factors (PTDFs). PTDFs are used to determine the sensitivities of transmission line flow to a single power transfer where as TLR sensitivity of the flow on single transmission element to various transactions in the system. In the method of congestion alleviation using load curtailment, TLR sensitivities at all the load bases for the most over loaded line are considered.

TLR sensitivity at a bus $\mathrm{k}$ for a congested line $\mathrm{i}-\mathrm{j}$ is given by equation

$$
\mathrm{S}_{\mathrm{ij}}{ }^{\mathrm{k}}=\frac{\Delta P_{i j}}{\Delta P_{k}}
$$

Where

$\Delta P i j$ is the excess power flow on line $\mathrm{i}-\mathrm{j}$

$$
\Delta P_{i j}=P_{i j}-\overline{P_{l j}}
$$

Where

$P_{i j}$ : Actual power flow through line $\mathrm{i}-\mathrm{j}$

$\overline{P_{\imath \jmath}}$ : Flow limit of transmission line $\mathrm{i}-\mathrm{j}$

The new load $P_{k}^{\text {new }}$ at bus k can be obtained by

$P_{k}^{\text {new }}=P_{k}-\frac{s_{i j}^{k}}{\sum_{i=1}^{N} s_{i j}^{k}} \overline{\Delta P_{u j}}$

$P_{k}^{\text {new }}=$ load after curtailment at bus $\mathrm{K}$

$P_{k}=$ load before curtailment at bus $\mathrm{K}$

$\mathrm{S}_{\mathrm{ij}}{ }^{\mathrm{k}}=$ =sensitivity of power flow on line i-j

due to load change at bus $\mathrm{k}$

$\mathrm{N}=$ total number of load buses.

\section{SIMULATION RESULTS}

In this study an IEEE 9 bus system has been analysed for congestion management by the optimal location of FACTS device such as TCSC using the power world simulator software based on sensitivity indices approach

Fig 5.1. Indicates the single line diagram of an IEEE 9 bus system drawn in power world simulator. 


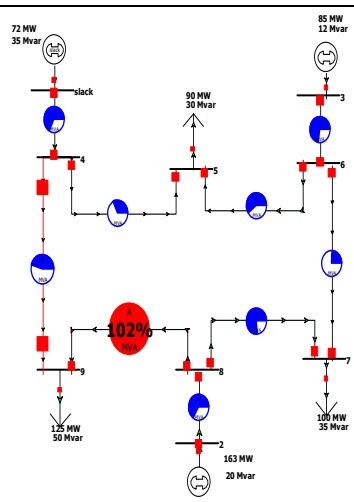

Fig. 5.1. Modified IEEE 9 bus system

From the above figure it was found that the line 8-9 in the system is in congested condition .In order to relieve the system from congested condition FACTS device such as Thyristor controlled series compensator (TCSC) is placed in one of the lines. A reactive power loss sensitivity based approach is used here for optimal placement of this device.

The sensitivity indices for the congested 9 bus system were tabulated below.

Table 5.1 OPF result without TCSC

\begin{tabular}{|l|l|l|l|}
\hline LINES & $\begin{array}{l}\text { FROM } \\
\text { BUS }\end{array}$ & TO BUS & $\begin{array}{l}\text { LOADABILITY } \\
(\%)\end{array}$ \\
\hline 1 & 1 & 4 & 66.69 \\
\hline 2 & 4 & 5 & 39.13 \\
\hline 3 & 5 & 6 & 61.08 \\
\hline 4 & 3 & 6 & 71.58 \\
\hline 5 & 4 & 9 & 53.60 \\
\hline 6 & 8 & 7 & 77.09 \\
\hline 7 & 2 & 8 & 65.68 \\
\hline 8 & 8 & 9 & 102.02 \\
\hline 9 & 6 & 7 & 31.95 \\
\hline
\end{tabular}

The result of the OPF run on the test network is shown in the above table 3.1. From the OPF it was found that the real power flow in line 8 was 102.02 which is more than line loading limit.

\subsection{Reactive power loss sensitivity index of IEEE 9 bus system}

Table 5.2 sensitivity factors

\begin{tabular}{|c|c|c|c|c|c|}
\hline \multirow[t]{2}{*}{ LINE } & \multirow{2}{*}{$\begin{array}{l}\text { FROM } \\
\text { BUS }\end{array}$} & \multirow{2}{*}{$\begin{array}{l}\text { TO } \\
\text { BUS }\end{array}$} & \multicolumn{3}{|c|}{ SENSITIVITY INDEX $\left(a_{\mathrm{ij}}\right)$} \\
\hline & & & $\begin{array}{l}\text { TCSC } \\
\text { (20\% comp) }\end{array}$ & $\begin{array}{l}\text { TCSC } \\
\text { (40\% comp) }\end{array}$ & $\begin{array}{l}\text { TCSC } \\
\text { (60\% comp) }\end{array}$ \\
\hline 1 & 1 & 4 & -0.64546 & -0.65990 & -0.66714 \\
\hline 2 & 4 & 5 & -0.12684 & -0.12385 & -0.10357 \\
\hline 3 & 5 & 6 & -0.35638 & -0.34761 & -0.26126 \\
\hline 4 & 3 & 6 & -0.7407 & -0.73801 & -0.74401 \\
\hline 5 & 4 & 9 & -0.26500 & -0.26851 & -0.25751 \\
\hline 6 & 7 & 8 & -0.59930 & -0.60259 & -0.57969 \\
\hline 7 & 8 & 2 & -2.6885 & -2.68448 & -2.67225 \\
\hline 8 & 8 & 9 & -0.75807 & -0.75434 & -0.62786 \\
\hline 9 & 6 & 7 & -0.07522 & $\begin{array}{l}-0.07902 \\
\end{array}$ & -0.07835 \\
\hline
\end{tabular}


From the above table the lines having the most positive loss sensitivity index is chosen for the placement of TCSC devices. Hence lines 2 and 9 are selected from the table. TCSC device in the inductive mode of operation are connected in series with these two lines, with inductive reactance of $60 \%$ of the line reactance each have been considered.

Table5.3 Power flow list.

\begin{tabular}{|l|l|l|l|l|}
\hline lines & $\begin{array}{l}\text { Power } \\
\text { flow } \\
\text { without } \\
\text { TCSC } \\
\text { (MW) }\end{array}$ & $\begin{array}{l}\text { TCSC } \\
\text { with } \\
20 \% \\
\text { comp }\end{array}$ & $\begin{array}{l}\text { TCSC } \\
\text { with } \\
40 \% \\
\text { comp }\end{array}$ & $\begin{array}{l}\text { TCSC } \\
\text { with } \\
60 \% \\
\text { comp }\end{array}$ \\
\hline 1 & 72.09 & 72.09 & 72.09 & 72.11 \\
\hline 2 & 31.03 & 29.54 & 28.20 & 27.00 \\
\hline 3 & 60.29 & 62.25 & 63.64 & 64.90 \\
\hline 4 & 85 & 85.00 & 85.00 & 85.00 \\
\hline 5 & 41.06 & 42.55 & 43.89 & 45.10 \\
\hline 6 & 76.29 & 77.86 & 79.27 & 80.54 \\
\hline 7 & 163 & 163 & 163 & 163 \\
\hline 8 & 86.71 & 85.14 & 83.73 & 82.46 \\
\hline 9 & 24.31 & 22.75 & 21.36 & 20.10 \\
\hline
\end{tabular}

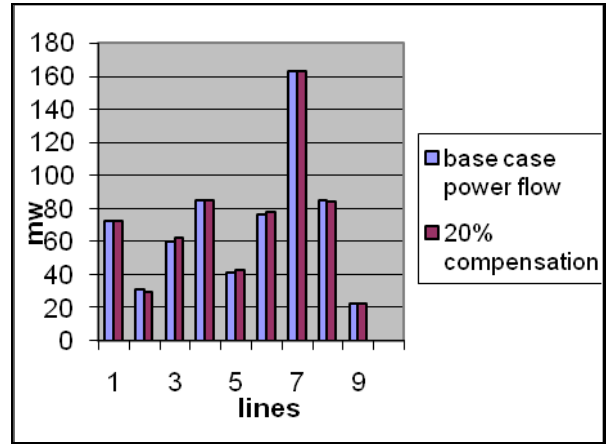

Fig 5.2. Comparison of power flows with (20\%comp) and without TCSC.

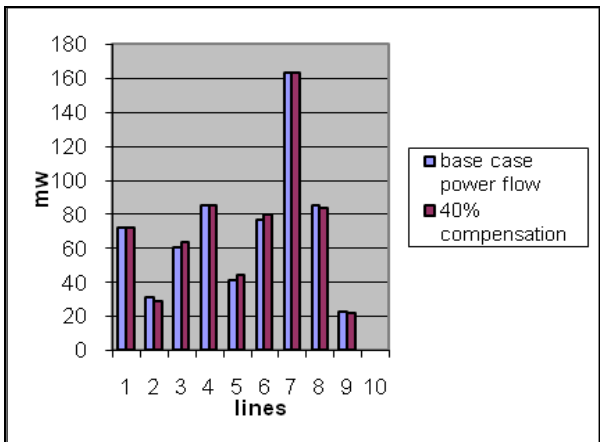

Fig 5.3 Comparison of power flows with (40\%comp) and without TCSC.

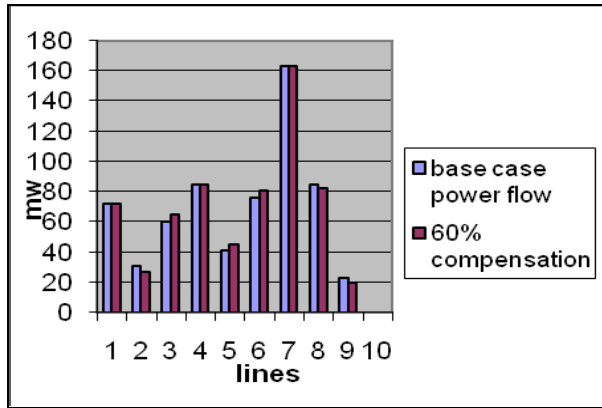

Fig 5.4 comparison of power flows with (60\% comp) and without TCSC. 
When TCSC (20\%) is placed in the lines 4-5 and 6-7, it removes the congestion present in the line 8-9 from $102 \%$ to $100 \%$. Again when the lines 4-5 and 6-7 were being compensated by $40 \%$, the congestion in the line $8-9$ got relieved from $100 \%$ to $99 \%$ and the congestion in the line $8-9$ is relieved to $97 \%$ when the lines $4-5$ and 6-7 were compensated by $60 \%$. From the results we can observe that placing the TCSC in the optimal location relieves the congestion in the modified IEEE 9 bus system.

\subsection{Transmission line relief (TLR) sensitivity method}

This transmission line relief method is based on load curtailment. In this method of congestion management, TLR sensitivities at all the load buses for the most overloaded line are considered. An IEEE 9 bus congested system is considered here.

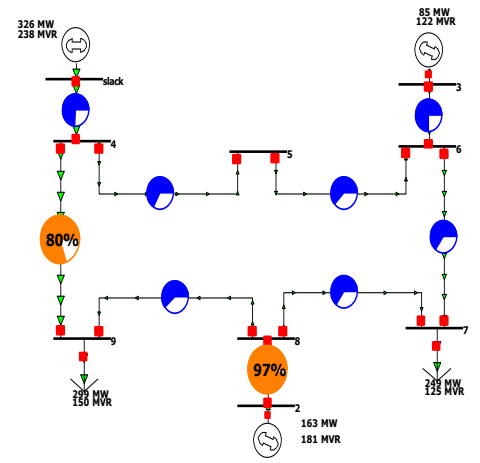

Fig5.5 Congested IEEE 9 bus system.

The TLR values of congested lines of a 9 bus system are tabulated below.

Table: 5.4 TLR sensitivities

\begin{tabular}{|l|l|l|l|}
\hline BUSES & $\begin{array}{l}\text { LINE (4- } \\
9\end{array}$ & $\begin{array}{l}\text { LINE (7- } \\
8)\end{array}$ & $\begin{array}{l}\text { LINE (7- } \\
6)\end{array}$ \\
\hline 1 & 0 & 0 & 0 \\
\hline 2 & 0.639 & -0.361 & 0.361 \\
\hline 3 & 0.385 & 0.385 & -0.385 \\
\hline 4 & 0 & 0 & 0 \\
\hline 5 & 0.135 & 0.135 & -0.135 \\
\hline 6 & 0.385 & 0.385 & -0.385 \\
\hline 7 & 0.533 & $\mathbf{0 . 5 3 3}$ & $\mathbf{0 . 4 6 7}$ \\
\hline 8 & 0.639 & -0.361 & 0.361 \\
\hline 9 & $\mathbf{0 . 8 7 5}$ & -0.125 & 0.125 \\
\hline
\end{tabular}

Load curtailment is to be done at the bus having most positive value. From the table the TLR sensitivity at bus 9 for the line 4-9 is most positive. So load curtailment of 9MW at bus 9 relieves the congestion of line 4-9 and similarly load curtailment at bus 7 relieves congestion from $97 \%$ to $90 \%$ of the line $8-2$

\section{CONCLUSION}

Congestion management is the important issue in the deregulated power system.TLR sensitivity approach have been examined by load curtailment and reduction of total system reactive power loss sensitivity indices are proposed for locating TCSC device to manage the congestion in deregulated electricity market. A power injection П-model is developed for TCSC and then reduction of reactive power loss sensitivity index is modified for the network containing a TCSC. The proposed methodologies are based on sensitivity that are by-product of OPF problem formulation. The proposed method was tested on modified IEEE 9 bus system.

\section{ACKNOWLEDGMENT}

The authors would like to thank QISCET, Ongole for providing the computer lab facility with necessary software. 


\section{REFERENCES}

1. A.S. Bawnakar, V.P. Rajderkar, Third International Conference on Emerging Trends, Compensator To Resolve Congestion Caused Problems".

2. L.Rajalakshmi, M.V.Suganyadevi, S. Parameswari,“ Congestion management in deregulated power system by locating series FACTS devices". International Journal of Computer Applications (0975 - 8887) Volume 13- No.8, January 2011.

3. De Oliveira E.J., Lima W.M., 1999 “Allocation of FACTS devices in a competitive environment", 13" PSCC, 1184-1190.

4. A.R.Abhyankar, Prof.S.A.Khaparde, IIT Bombay, "Introduction to deregulation in power industry".

5. A.H.Iranmahesh, M. Rashidi-Nejad And Gharaveisi, M. Shojaee, "Congestion Relief Via intelligent Coordination Of TCSC \& SVC",

6. Kumar a., Srivatsava S.C., singh S.N., 2004. "A Zonal Congestion Management Approach using Real and Reactive Power Rescheduling", IEEE Transactions on Power systems, vol. 19, No. 1.

7. Ch. Schaffner, G. Andersson, Swiss Fedaral Institute of Technology(ETH), zurich, Switzerland, "Use of FACTS devices for congestion management in liberalized electricity market".

8. G.Glanzmann*, G.Andersson, ETH Zurich, Switzerland." Using FACTS devices to resolve congestionin transmission grids".

9. N.G. Hingaroni and L. Gyugyi. "Understanding FACTS concepts and technology of flexible ac transmission systems. IEEE Press, New York, 2000.

10. Seyed Mohammad Hosseini Nabavi, Nazanin Alsadat Hosseinipoor,Somayeh Hajforoosh, International Journal of Computer Applications(0975-8887) vol6-No.6, September 2010. "Social Welfare Maximization by optimal locating and sizing of TCSC for Congestion Management in Deregulated power markets".

11. Huijuan Li, Fangxing Li, Pei Zhang, Xiayang. Presentation at 2009 IEEE BucharestPower Tech conference, June $28^{\text {th }}-$ july $2^{\text {nd }}$ „Bucharest, Romania. “ Optimal utilization of Transmission Capacity to Reduce Congestion with Distributed FACTS”.

12. Manasarani Mandala and C.P. Gupta, $16^{\text {th }}$ National Power systems Conference, $15^{\text {th }}-17^{\text {th }}$ December, 2010 . "Comparative Studies of Congestion Management in Deregulated Electricity Market".

13. Shmuel S. Oren, University of California at berkely. "Transmission Pricing and Congestion Management : Efficiency , Simplicity and Open Access".

14. H. singh, S. Hao, and A.papalexopoulos, "Transmission congestion management in competitive electricity markets", IEEE Trans. on power systems, 1998, vol. 13, No.2,pp. 672- 680.

15. Naresh Acharya, M. Mithulananthan, "Locating Series FACTS devices For Congestion Management In Deregulated Electricity Market".

16. Power World Simulator, Power World Corporation, version 11.0, Evaluation and University Educational Use, URBANA, IL 61801. 